\title{
CLINICAL AND RADIOGRAPHIC EVALUATION OF IMMEDIATE IMPLANT PLACEMENT WITH AND WITHOUT "BONE RINGS" IN ESTHETIC ZONE
}

\author{
Nihal A. Elnebairy ${ }^{1} B D S$, Magued H. Fahmy ${ }^{2} P h D$, Nevien S. Mohamed ${ }^{2} P h D$
}

\begin{abstract}
INTRODUCTION: Immediate implant placement is now accepted in clinical dentistry for reconstruction of partially or completely edentulous mandible or maxilla.

OBJECTIVES: The aim of the study was to evaluate the role of Maxgraft bone rings on the marginal bone level around dental implants placed in fresh extraction sockets.

MATERIALS AND METHODS: A randomized clinical trial was carried out on fourteen cases with freshly extracted sockets with age range 20 to 50 years. There were 2 groups, study group and control group, the sockets of the study group were filled with the new "Maxgraft bone ring" and an immediate placement of implants were carried out in the graft site, while the control group sockets had immediate implant placement alone. A clinical and radiological evaluation were carried out immediately postoperatively, after 3 \& 6 months to assess the osteointegration of the implant placed and to measure the level of the marginal bone around the implant. After 6 months final prosthesis was delivered.

RESULTS: Radiographic evaluation revealed increase in marginal bone level around implants placed in the Maxgraft bone rings than those placed alone with statistical significance (p1 $=0.008)$

CONCLUSIONS: Increase in marginal bone level using the Maxgraft bone rings due to its osteoconductive properties supporting natural and controlled tissue remodeling together with the trabecular structure of the cancellous bone within the graft allow optimal graft revascularization, rapid formation of new bone tissue and bone remodeling.
\end{abstract}

KEYWORDS: Alveolar bone, Fish oil, Induced rheumatoid arthritis, Freund's complete adjuvant

1-B.D.S. Faculty of Dentistry Alexandria University

2-Professor of Oral and Maxillofacial Surgery, Faculty of Dentistry Alexandria University

\section{INTRODUCTION}

Immediate implant placement is now accepted in clinical dentistry for reconstruction of partially or completely edentulous mandible or maxilla $(1,2)$. This procedure has several advantages such as prevention of bone resorption, reduced number of surgical visits, better esthetics and higher patient satisfaction compared with delayed placement of implants.

However, because of the nature of this treatment method, a higher risk for complications and failures might be expected (3).

Dental implants require sufficient bone to be adequately stabilized. For some patients, implants treatment would not be an option without bone augmentation. A variety of materials and surgical techniques are available for bone augmentation (4).

To ensure the osseointegration of the entire implants, bone replacement grafts either autogenous, allogenic, xenogenic, membranes, synthetic bone substitutes or combination of them have been used to achieve in such defects $(5,6)$.

The chin bone disc was first introduced to the surgical field for the bony closure of oro-antral fistulas (7). The chin bone disc was recently modified to a ring shape for the three-dimensional augmentation of defective sockets with simultaneous implant placement; this technique proved successful in bone augmentation and implant integration $(8,10)$.

Autogenous block bone grafts thus remained the material of choice in the majority of cases with vertical bone deficiency (11). Bone ring technique was originally described as a single-staged procedure for vertical augmentation, in which an autogenous cortical block bone graft is stabilized with a simultaneously inserted dental implant (12).

Maxgraft bone ring is a human originated material, this allograft is available in blocks (cortico-spongious and spongious) and as granulates as well. It's an interesting alternative for harvesting autogenous bone in some cases. Bone for this material is collected from living donor patients who are accepted for hip joint replacement. After they have undergone very strict and controlled EU regulation tests and cleaning procedures the bone is used to create the material Maxgraft (13).

The present study thus aimed to evaluate clinical and radiographic effect of Maxgraft bone rings on the marginal bone level around dental implants in fresh extraction sockets.

\section{MATERIALS AND METHODS}

The ethical clearance was obtained by the ethical committee before the study began, and the selected patients were informed about the nature of the study and the informed consent was obtained.

\section{Patients}

A randomized clinical trial was conducted on 14 patients who were indicated for single rooted tooth extraction in Maxilla or Mandible, they were selected from those admitted to the Oral and Maxillofacial Surgery Department, Faculty of Dentistry, Alexandria University.

Patients were divided in to 2 groups: Study group; Seven extraction sockets of single rooted teeth of seven patients 
were grafted with Maxgraft bone ring together with immediate implant placement and Control group; Seven extraction sockets of single rooted teeth of seven patients had immediate implant placement without Maxgraft bone ring. Patients with age range 20 to 50 years, nonsmokers, with good oral hygiene were included in this study, while patients with Active infection (periodontitis or mucosal infection), chemotherapy, radiotherapy, alcohol, drug abuse, systemic disorders (uncontrolled Diabetes mellitus, autoimmune diseases. etc.) and bone diseases were excluded.

\section{Materials}

Fourteen Biohorizons Mount-free Tapered Internal dental implants (Birmingham, USA) were placed either in the maxillary or the mandibular arch. The implants used in this study were characterized by dual affinity Laser-Lok surface offers flexible implant placement, providing excellent bone maintenance and a stable soft tissue seal. Aggressive buttress threads and anatomically tapered body provide compressive loading and excellent primary stability.

Seven sterile Maxgraft bonerings (Botiss, Germany) (fig.1) with height of $10 \mathrm{~mm}$ and diameter of $7 \mathrm{~mm}$, were placed using Maxgraft surgical kit (Botiss, Germany) (fig.2) which is composed of two convenient sizes of trephines, which precisely fit together with the Maxgraft bone ring diameters. The planators allow paving of the local bone to create a congruent and fresh contact surface of the implant area. The diamond disc and the diamond tulip serve to shape the Maxgraft bone ring for excellent adjustment to the local bone and for improved soft tissue healing. The osteoconductive properties of Maxgraft supporting natural and controlled tissue remodeling and preserved biomechanical properties ensures optimal graft revascularization, rapid formation of new bone tissue and bone remodeling.

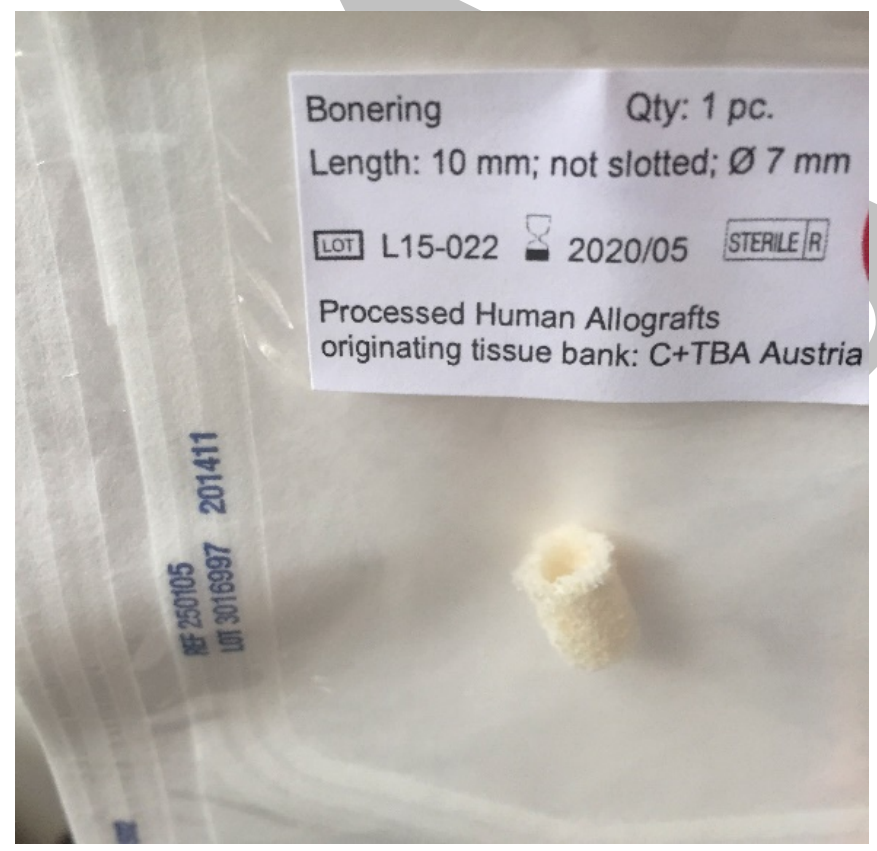

Figure (1): Showing Maxgraft bone ring

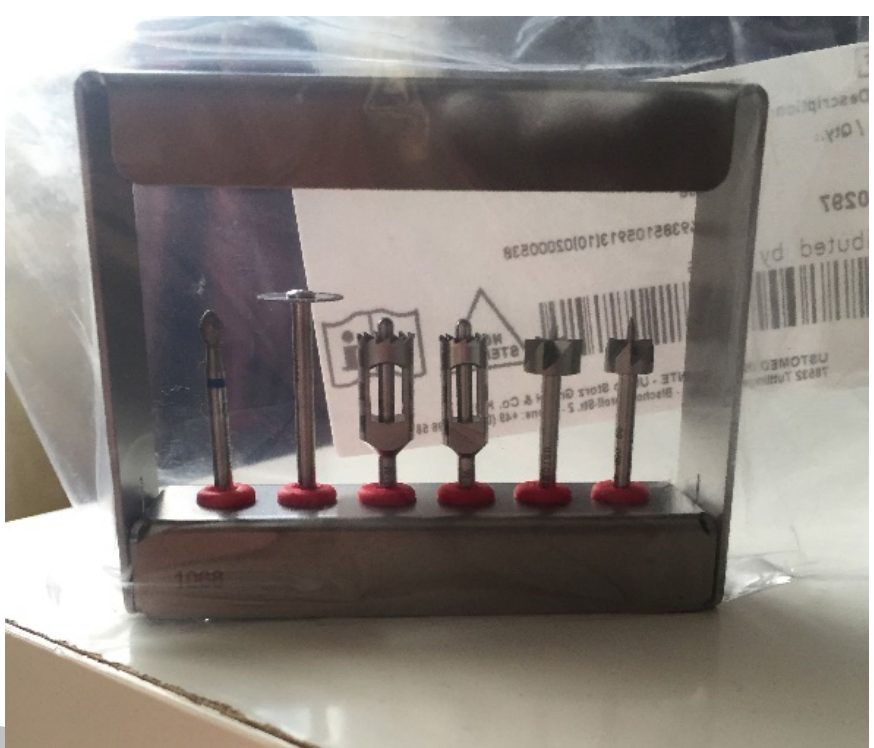

Figure (2): Showing Maxgraft surgical kit

Methods

A. Pre-surgical phase

Initial periodontal therapy

Oral hygiene instructions were given; scaling and root planning were done.

\section{Preliminary evaluation}

Each patient was investigated clinically and radiographically. All patients were subjected to a detailed history taking including: personal data, medical history and dental history. Local visual examination, palpation of the entire oral and paraoral tissues was done to ensure right selection of the patients, then the teeth to be extracted were evaluated.

Primary alginate impression taking for both arches and casting diagnostic study models to evaluate interarch relationship, interocclusal space that could accommodate the implant abutment and the future crown restoration both clinically and on the study model.

Cone beam computed tomography CBCT was done for each patient preoperatively to evaluate the quantity and the quality of bone present and to detect any hidden bony abnormalities and measurement of the socket depth and width before extraction.

\section{B. Surgical phase}

All patients were operated under local anaesthesia with UbistesinTM forte (Articaine HCL with epinephrine 1:100,000, 3M ESPE, Seefeld, Germany), atraumatic extraction was performed using forceps, to preserve the available alveolar bone. Full thickness pyramidal flaps were elevated. For the study group, after determination of the position of the implants by the pilot drill, the ring beds were prepared with the trephine bur, then the planetor bur was used to allow an even paving of the local bone for optimal contact with Maxgraft bone ring and in addition, to remove the cortical layer of bone for improved graft revascularization, bone rings were placed in the surgical sites(fig3). 


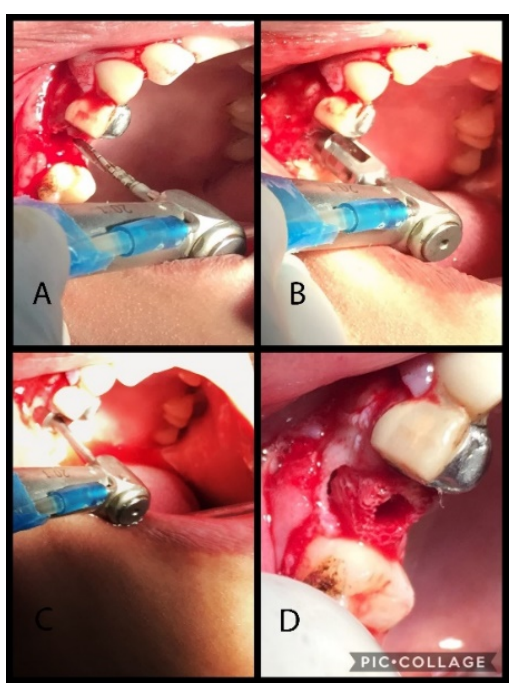

Figure (3a, 3b, 3c, 3d): Showing surgical steps of the study group including, use of pilot bur, use of trephine and plantor surgical burs \& Maxgraft bone ring placement.

Bone rings were drilled by implant drills, performed as recommended by the manufacturer (Drilling speed was 800 RPM), then the implant fixtures were placed in them using hand wrench and then finally seated down to full depth using ratchet wrench(fig4a,4b), implant mounts were removed, smart pegs were attached with sizes corresponded to each implant size (Type 32 smart peg for the yellow platform implants) and primary implant stability was determined using Resonance Frequency Analysis Device (OSSTELL) (Goteborg, Sweden), healing abutments were placed and suturing with black silk suture was performed.

For the control group, immediate implant placement was performed alone, implant mounts were removed, smart pegs were attached with sizes corresponded to each implant size and primary implant stability was determined using Resonance Frequency Analysis Device (OSSTELL) (Goteborg, Sweden) and finally healing abutments were placed and suturing with black silk suture was performed.

\section{Postsurgical phase}

Postoperative instructions including, extraoral ice packs during the first day every one hour and maintain daily routine oral hygiene after surgery and patients were instructed to eat a soft diet for 7 days.

All patients received Postoperative medications including:

Broad spectrum oral antibiotics: Amoxicillin875 mg / Clavulanic acid 125mg (Augmentin 1gm Tablets, Medical Union Pharmaceuticals (MUP), GlaxoSmithKline, Cairo, Egypt) in a dose of one capsule every 12 hours for a week. Non-steroidal anti-inflammatory drugs Ibuprofen $400 \mathrm{mg}$ (Brufen tablet 400mg Abbott, Cairo, Egypt) at a dose of one tablet every eight hours for four days.

Warm chlorhexidine gluconate solution (Hexitol mouth wash, Arab Drug Co., Cairo, Egypt) as a mouthwash for a period of 2 weeks to enhance plaque control.

\section{Follow up phase}

\section{Clinical evaluation}

Early follow up was performed immediately after graft and implant placement, at a period of 1 week to detect any Pain according to Numerical Rating scale from (0-10).

Each patient was evaluated clinically for:

Presence of pain or infection at a period of one week.
Assesement of implant stability using Resonance Frequency Analysis Device (OSSTELL) (Goteborg, Sweden), immediately after implant placement, 3 and 6 months later. A measurement of Osstell is displayed as implant stability quotient (ISQ) from 1 to 100, where 100 signify the highest implant stability.

\section{Radiographic Evaluation:}

Cone Beam Computed Tomography (CBCT) was taken immediately after surgery (fig5a), 3 and 6 months postoperatively (fig5b) to determine marginal bone level around the placed implant by the aid of OnDemand3D ${ }^{\mathrm{TM}}$ software CBCT analyzing software.

Assessment of marginal bone height around the implants

Mesial \& distal bone height changes around the implants were evaluated using the linear measurement system supplied by CBCT software.

\section{Measurements were taken as follows:}

\section{Setting measurement scale:}

*The dialog scale was used to define the spatial scale of the active image, so measurement results could be presented in calibrated units such as: millimeters.

*Length of the implant was used as a known measurement in mms.

*By entering the known distance and the unit of measurements in the set scale dialog, the CBCT automatically changes the distance in pixels to mms.

The distance from the bottom of the implant fixture and the first point of the bone -implant contact mesially and distally were used to represent the level of marginal bone measured, that was done immediately after surgery to mark a baseline, 3 and 6 months later to measure the level of marginal bone level.

Mean, standard deviation, minimum and maximum readings were automatically displayed by the system.

\section{E. Prosthetic phase}

After six months, the final prosthesis was delivered over the abutments and functional loading was applied on the osseointegrated implants (fig4c,4d).

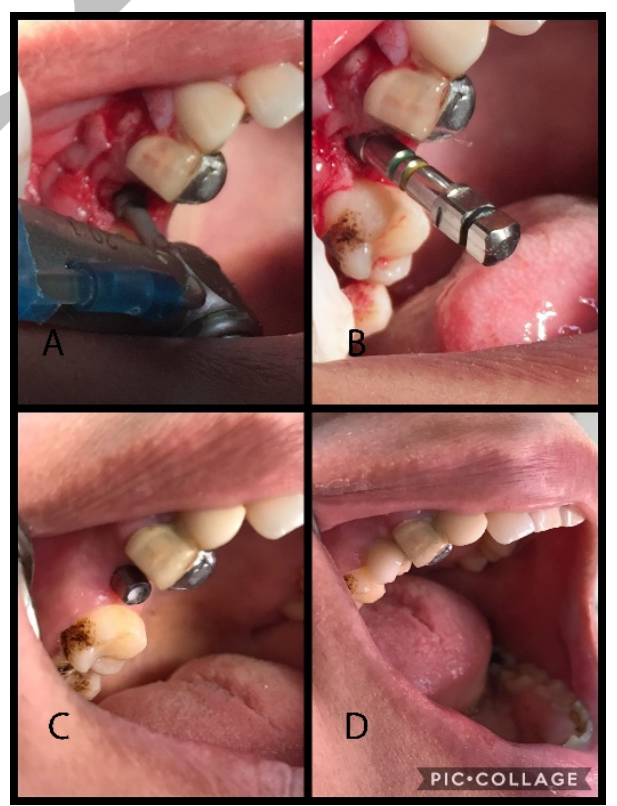

Figure (4a, ab, 4c, 4d): Showing implant drills used within the bone ring, implant in place within the Maxgraft bone ring, final abutement in place \& final prosthesis. 


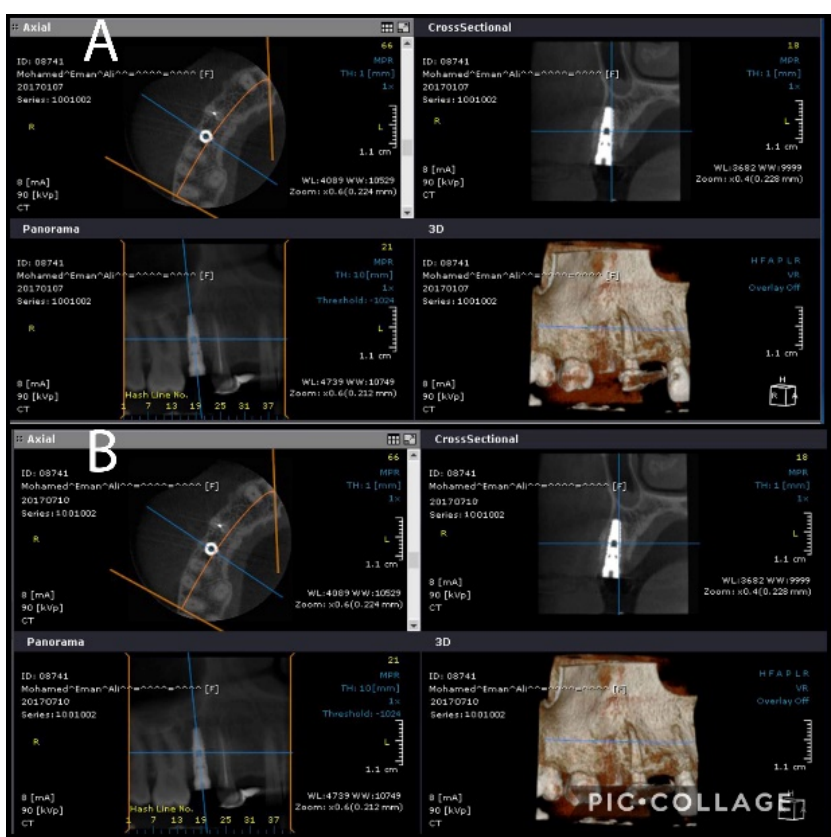

Figure (5a, 5b): Showing the Cone beam computed tomography of the study group immediately after surgery and after six months.

\section{Statistical analysis of the data (14)}

Data were fed to the computer and analyzed using IBM SPSS software package version 20.0. (Armonk, NY: IBM Corp) (15), qualitative data were described using number and percent. Quantitative data were described using range (minimum and maximum), mean, standard deviation and median. Significance of the obtained results was judged at the $5 \%$ level.

The used tests were:

Student t-test

For normally quantitative variables, to compare between two studied groups.

Paired t-test

For normally quantitative variables, to compare between two periods.

\section{RESULTS}

Fourteen patients with carious maxillary or mandibular single-rooted teeth indicated for extraction were involved in this study. Their ages ranged from 20 to 50 years with mean age of 36 years. The ratio between males and females was 3:4 (six males and eight females). Eight implants were inserted in upper arch in the central, canine and 2nd premolar region having diameters of $3.8 \mathrm{~mm}$ and length of $12.0 \mathrm{~mm}$ and $15.0 \mathrm{~mm}$. Six implants were inserted in the lower 1st and 2nd premolar region having diameters of 3.8 and lengths of $10.5 \mathrm{~mm}$ and $12.0 \mathrm{~mm}$.

All patients were followed up for six months and the results were registered as regards: Clinical and Radiographic evaluation

\section{I)Clinical results}

\section{Presence of pain, infection or swelling}

Pain was evaluated immediately after extraction, bone grafting and implant placement at a period of one week to detect any pain according to Numerical Rating scale from $(0-10)$ where $0=$ no pain and $10=$ worst pain $(16)$, infection or swelling also evaluated.

After the procedure, all patients experienced mild to moderate pain at the surgical sites with mean pain severity 7. The mean pain duration was $1.9 \pm 0.6$. (pain duration was measured by days)
All patients continued the follow up period without any signs of infection or swelling.

\section{Implant stability quotient (ISQ)}

A measurement of Osstell is displayed as implant stability quotient (ISQ) from 1 to 100 , where 100 signify the highest implant stability (Table 1).

Table (1): Comparison between the studied periods according to peri-implant probing depth.

\begin{tabular}{|c|c|c|c|c|}
\hline \multirow[b]{2}{*}{$\begin{array}{l}\text { Peri-implant } \\
\text { probing depth }\end{array}$} & \multicolumn{2}{|c|}{ Study (n= 07) } & \multicolumn{2}{|c|}{ Control $(n=07)$} \\
\hline & $3^{\text {month }}$ & month $^{\text {th }}$ & $3^{\text {month }}$ & month $^{\text {th }}$ \\
\hline Min. - Max. & $1.5-2.25$ & $0.75-2.0$ & $2.5-3.0$ & $1.5-2.5$ \\
\hline Mean \pm SD & $\begin{array}{c}1.75 \pm \\
0.26\end{array}$ & $\begin{array}{c}1.25 \pm \\
0.4\end{array}$ & $\begin{array}{c}2.7 \pm \\
0.24\end{array}$ & $\begin{array}{c}2.0 \pm \\
0.31\end{array}$ \\
\hline Median & 1.75 & 1.25 & 2.5 & 1.75 \\
\hline $\mathbf{p}_{1}$ & \multicolumn{2}{|c|}{$0.006^{*}$} & \multicolumn{2}{|c|}{$0.003^{*}$} \\
\hline $\mathbf{p}_{2}$ & & & $0.02^{*}$ & $<0.001^{*}$ \\
\hline
\end{tabular}

Immediately after bone graft and implant placement, the mean ISQ value for the study group was $58.0 \pm 1.5$ with a minimum recorded value of 55.0 and a maximum recorded value of 60.0 , while the mean ISQ value for the control group was $61.4 \pm 1.4$ with a minimum recorded value of 59.0 and a maximum recorded value of 64.0. This difference in the implant stability quotient between the study and control groups immediately after bone graft and implant placement was found to be statistically significant. (P1=0.012)

Three months later, the mean ISQ value for the study group was $65.3 \pm 1.4$ with a minimum recorded value of 63.0 and a maximum recorded value of 67.0 , while the mean ISQ value for the control group was $69.7 \pm 1.03$ with a minimum recorded value of 68.0 and a maximum recorded value of 71.0. This difference in the implant stability quotient between the study and control groups after three months of implant placement was found to be statistically significant. $(\mathrm{P} 1=0.0004)$

Six months later, the mean ISQ value for the study group was $68.0 \pm 1.4$. with a minimum recorded value of 68.0 and a maximum recorded value of 72.0 , while the mean ISQ value for the control group was $77.6 \pm 1.17$ with a minimum recorded value of 76.0 and a maximum recorded value of 79.0. This difference in the implant stability quotient between the study and control groups after six months of implant placement was found to be statistically significant. $(\mathrm{P} 2=0.00004)$

\section{Radiographic results}

Marginal bone height at the mesial and distal aspects of all implants were measured immediately after surgery, three and six month later using:

Cone beam CT films analyzed by OnDemand 3D software Mean marginal bone level and standard deviation values recorded in millimeters, tabulated and statistically analyzed (Table 2 fig 6)

Immediately post operatively, the mean marginal bone level value for both groups were $0 \pm 0$ with minimum recorded value of 0 and maximum recorded value of 0 , 
showing no statistically significant difference between the two groups.

On the third month, the mean marginal bone level value for the study group was $0.62 \pm 0.08$ with minimum recorded value of 0.4 and maximum recorded value of 0.74 while the mean marginal bone level value for the control group was $0.38 \pm 0.12$ with minimum recorded value of 0.3 and maximum recorded value of 0.7 . This difference in marginal bone level value between the study and control groups was statistically significant $(\mathrm{P}=0.02)$.

On the sixth month, the mean marginal bone level value for the study group was $1.18 \pm 0.18$ with minimum recorded value of 0.9 and maximum recorded value of 1.5 , while the mean marginal bone level value for the control group was $0.76 \pm 0.13$ with minimum recorded value of 0.5 and maximum recorded value of 1.0 . This difference in marginal bone level value between the study and control groups was statistically significant $(\mathrm{P}=0.008)$.

Table (2): Comparison between the two studied groups according to implant stability quotient (ISQ).

\begin{tabular}{|c|c|c|c|c|c|c|}
\hline \multirow[b]{2}{*}{$\begin{array}{c}\text { Implant } \\
\text { stability } \\
\text { quotient } \\
\text { (ISQ) }\end{array}$} & \multicolumn{3}{|c|}{ Study $(n=10)$} & \multicolumn{3}{|c|}{ Control $(n=10)$} \\
\hline & $\begin{array}{c}\text { Immediat } \\
\text { ely after } \\
\text { implant } \\
\text { placed }\end{array}$ & $\begin{array}{c}3 \\
\text { months } \\
\text { later }\end{array}$ & $\begin{array}{c}6 \\
\text { months } \\
\text { later }\end{array}$ & $\begin{array}{c}\text { Immediatel } \\
\mathrm{y} \text { after } \\
\text { implant } \\
\text { placed }\end{array}$ & $\begin{array}{c}3 \\
\text { months } \\
\text { later }\end{array}$ & $\begin{array}{c}6 \\
\text { months } \\
\text { later }\end{array}$ \\
\hline $\begin{array}{c}\text { Min. - } \\
\text { Max. }\end{array}$ & $\begin{array}{c}55.0- \\
60.0\end{array}$ & $\begin{array}{c}63.0- \\
67.0\end{array}$ & $\begin{array}{c}68.0- \\
72.0\end{array}$ & $59.0-64.0$ & $\begin{array}{c}68.0- \\
71.0\end{array}$ & $\begin{array}{c}76.0- \\
79.0\end{array}$ \\
\hline $\begin{array}{c}\text { Mean } \pm \\
\text { SD. }\end{array}$ & $58.0 \pm 1.5$ & $\begin{array}{c}65.3 \pm \\
1.4\end{array}$ & $\begin{array}{c}69.7 \pm \\
1.4\end{array}$ & $61.4 \pm 1.59$ & $\begin{array}{c}69.7 \pm \\
1.03\end{array}$ & $\begin{array}{c}77.6 \pm \\
1.17\end{array}$ \\
\hline Median & 58.0 & 65.0 & 70.0 & 61 & 70 & 78 \\
\hline P1 & & & & 0.012 & 0.0004 & 0.00004 \\
\hline
\end{tabular}

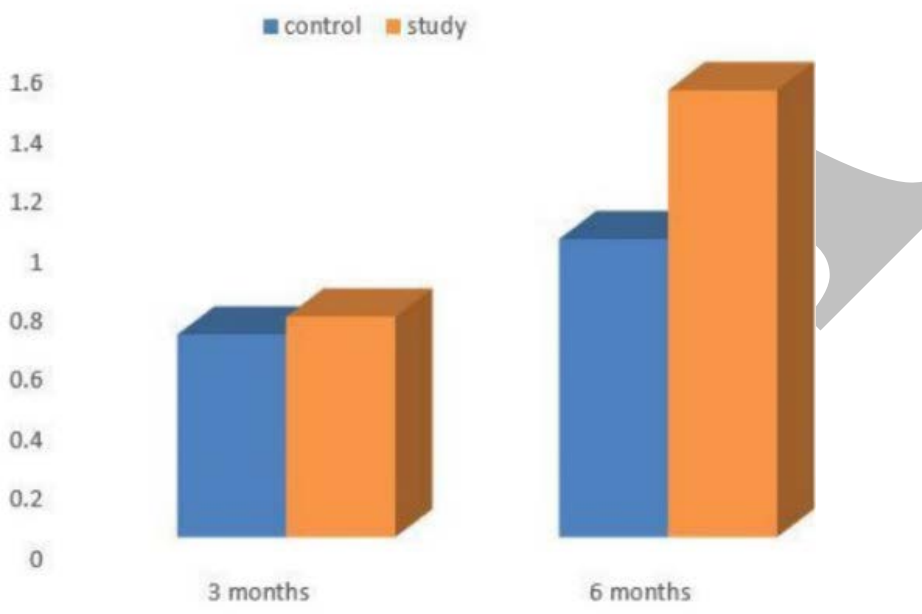

Figure (6): Comparison between the study group and the control group according to the marginal bone height

\section{DISCUSSION}

The present study was conducted on fourteen patients having badly destructed single rooted tooth in the maxillary or the mandibular arch, selected from those admitted to Oral and Maxillofacial Surgery Department, Faculty of Dentistry, Alexandria University.

All study group patients were subjected to minimalinvasive procedures, Graft/bed proximity was achieved in this technique through preparation of the sockets using trephine bur and plantor bur that were supplied by the Maxgraft surgical kit, thus allowing the bone ring to be fitted accurately in its recipient site with adequate stability and maximum surfaces of bony contact. This agreed with the findings of Marx (17), who emphasized the importance of graft stability during the early phases of bone healing and the reflection of this on early vascularization and graft incorporation.

Low speed, high torque hand piece was used for the preparation of the implant bed, and the drilling was performed under irrigation using cold normal saline for proper cooling and to avoid overheating of the bone tissue which would compromise osseointegration. This was supported by Strbac et al (18).

The application of tapered implants and progressive lateral bone compression during drilling are thought to improve the implant to bone contact, implant stability, and osseointegration. As Petrie et al (19) had proven during the course of their study.

In the present study, comparison between the two studied groups revealed statistically significant difference concerning the implant stability quotient throughout the study period. This was supported by Sim and Lang (20) who found that the development of the resonance frequency device had an important role to detect primary implant stability on immediately placed implants. However, Yoon et al (21) reported that both bone quality and surgical technique have influence on the primary implant stability.

Meredith (22) and Sennerby and Meredith (23) were first to propose Resonance Frequency Analysis device as a highly effective qualitative method to assess implant stability.

The mean of marginal bone level values of both groups showed a significant difference at the 6th month, similarly from a clinical point of view, a thin bone is expected to resorb due to the alterations that occur in the bundle bone after extraction in nongrafted extraction sockets. The nongrafted extraction sockets exhibit around 20\% loss of crest height as stated by Noumbissi et al (24). This observation is in agreement with the gain of height that was found in the ridge preservation studies from Iasella et al (25) and Vance et al (26) who already reported a gain of vertical average height of $1.3 \mathrm{~mm}$ and $0.7 \mathrm{~mm}$ respectively.

In a recent in vivo study that was carried out by SpinNeto et al (27) compared autologous bone block to allogenic bone block for lateral ridge augmentation, this study found allogenic blocks to be a good option for lateral ridge augmentation and gain in marginal bone level, as there were no significant differences found between the autologous and allogenic groups, thus allograft may substitute autogenous bone. This agreed with Waasdorp and Reynolds (28) who published a case report where an allogenic bone ring was used to augment an atrophic site. This study showed that allograft bone rings were satisfactory material to increase marginal bone level.

Ultimately the primary function of block bone graft material is to maintain space for angiogenesis and osteogenesis as were stated by Rose and Rosenberg (29) and Canuto et al (30) who said that bone formation is generated as an inflammatory response from the adjacent vital bone followed by angiogenesis and osteogenesis.

This shows that Maxgraft bone ring is an ideal allogenic grafting material regarding it's osteoconductive properties 
supporting natural and controlled tissue remodeling as stated by Blanco et al (31) who also mentioned that the trabecular structure of cancellous bone within Maxgraft bone ring allows optimal graft revascularization, rapid formation of new bone tissue and complete bone remodeling. In addition to single-stage augmentation and implant placement is the advantage of the ring technique in shortening the treatment time by several months compared with the two-stage classical approach as stated by Waasdorp and Reynolds (28)

\section{CONCLUSION}

Within the limitations of this study, the following conclusions can be addressed:

1. The Implant Stability quotient of implants placed in Maxgraft bone rings were lower than those implants placed alone at the beginning of the study as the implants placed in the Maxgraft bone rings were not placed entirely in native bone but partwise in the grafting material, therefore loading of the implants prior to six months of augmentation with bone rings should not be performed.

2. The increase in Marginal bone level around the implants placed in Maxgraft bone rings were higher than those implants placed alone at the end of the study period, this proves the osteoconductivity and new bone formation supported by Maxgraft bone rings.

\section{CONFLICT OF INTEREST}

The authors declare that they have no conflicts of interest.

\section{REFERENCES}

1. Schwartz-Arad D, Chaushu G. Placement of implants into fresh extraction sites: 4 to 7 years retrospective evaluation of 95 immediate implants. J Periodontol 1997; 68: 1110-6.

2. Schwartz-Arad D, Chaushu G. The ways and wherefores of immediate placement of implants into fresh extraction sites: A literature review. J Periodontol 1997; 68: 91523.

3. Schropp L, Isidor F. Timing of implant placement relative to tooth extraction. J Oral Rehabil 2007; 35: 3343.

4. Esposito M, Grusovin MG, Kwan S, Worthington HV, Coulthard P. Interventions for replacing missing teeth: bone augmentation techniques for dental implant treatment. Cochrane Database Syst Rev 2008; (3): CD003607.

5. Yukna RA, Castellon P, Saenz-Nasr AM, Owens K, Simmons J, Thunthy KH, et al. Evaluation of hard tissue replacement composite graft material. a ridge preservation/ augmantation material in conjunction with immediate hydroxyapatite coated dental implant. J Preiodontal 2003; 7: 679-86.

6. Martin K, Senpuku H, Hanada N, Ozawa H, Ejris S. Bone regeneration by recombinant human bone morphogenetic portion-2 around immediate implant: a pilot study in rates. J Oral Maxillofac Impl 2003; 18: 211-7.

7. Watzak G, Tepper G, Zechner W, Monov G, Busenlechner D, Watzek G. Bony press-fit closure of oro-antral fistulas: a technique for pre-sinus lift repair and secondary closure. J Oral Maxillofac Surg 2005; 63: 1288-94.

8. Stevens MR, Emam HA, El Alaily M, Sharawy M. Implant bone rings. One-stage threedimensional bone transplant technique: a case report. J Oral Implantol 2010; 1: 69-74.

9. Giesenhagen B, Yuksel O. Einzeitig behandeln mit Knochenringen. Vertikale Augmentation und Implantation in nur einem Eingriff. Implantol J 2010; 14: $50-2$

10. Kielhorn J, Roland B. Improved guided bone ring technique: a case report. EDI J 2011; 1: 42-3.

11. Blanco J, Mareque S, Linares A, Perez J, Munoz F, Ramos I. Impact of immediate loading on early bone healing at two-piece implants placed in fresh extraction sockets: an experimental study in the beagle dog. J Clin Periodontol 2013; 40: 421-9.

12. Boronat A, Carrillo C, Penarrocha M, Pennarocha M. Dental implants placed simultaneously with bone grafts in horizontal defects: a clinical retrospective study with 37 patients. Int J Oral Maxillofac Implants 2010; 25: 189-96.

13. Stevens MR, Emam HA, Alaily ME, Sharawy M. Implant bone rings. One-stage three-dimensional bone transplant technique: a case report. J Oral Implantol 2010; 36: 69-74.

14. Kotz S, Balakrishnan N, Vidakovic B. Encyclopedia of statistical sciences. 2nd ed. Hoboken, N.J.: WileyInterscience; 2006.

15. Kirkpatrick L, Feeney B. A simple guide to IBM SPSS statistics for version 20.0. Belmont, Calif.: Wadsworth, Cengage Learning; 2013.

16. Glavind L, Loe H. Errors in the clinical assessment of periodontal destruction. J Periodontal Res 1967; 2: 1804.

17. Marx RE. Bone and bone graft healing. Oral and maxillofacial surgery clinics of North America. 2007; 19(4):455-66.

18. Strbac GD, Unger E, Donner R, Bijak M, Watzek G, Zechner W. Thermal effects of a combined irrigation method during implant site drilling. A standardized in vitro study using a bovine rib model. Clin Oral Implants Res 2012; 25: 665-74.

19. Petrie CS, Williams JL. Comparative evaluation of implant designs: influence of diameter, length, and taper on strains in the alveolar crest-a three-dimensional finite-element analysis. Clin Oral Implants Res 2005; 16: 486-94.

20. Sim CP, Lang NP. Factors influencing resonance frequency analysis assessed by Osstell ${ }^{\mathrm{TM}}$ mentor during implant tissue integration: I. Instrument positioning, bone structure, implant length. Clinical oral implants research. 2010; 21(6):598-604.

21. Yoon HG, Heo SJ, Koak JY, Kim SK, Lee SY. Effect of bone quality and implant surgical technique on implant stability quotient (ISQ) value. J Adv Prosthodont 2011; 3: $10-5$

22. Meredith N. Assessment of implant stability as a prognostic determinant. Int J Prosthodont 1998; 11: 491501.

23. Sennerby I, Meredith N. Resonance frequency analysis: measuring implant stability and osseointegration. Compend Contin Educ Dent 1998; 19: 493-8. 
24. Noumbissi SS, Lozada JL, Boyne PJ, Rohrer MD, Clem $\mathrm{D}$, Kim JS, et al. Clinical, histologic, and histomorphometric evaluation of mineralized solventdehydrated bone allograft (Puros) in human maxillary sinus grafts. J Oral Implantol 2005; 31: 171-9.

25. Iasella JM, Greenwell H, Miller RL, Hill M, Drisko C, Bohra AA, et al. Ridge preservation with freeze-dried bone allograft and a collagen membrane compared to extraction alone for implant site development: a clinical and histologic study in humans. J Periodontol 2003; 74: 990-9.

26. Vance GS, Greenwell H, Miller RL, Hill M, Johnston H, Scheetz JP. Comparison of an allograft in an experimental putty carrier and bovine-derived xenograft used in ridge preservation: a clinical and histologic study in humans. Int J Oral Maxillofac Implants 2004; 19: 491-7.

27. Spin-Neto R, Stavropoulos A, Coletti FL, Faedda RS, Pereira LA, Marcantonio E. Graft incorporation and implant osseointegration following the use of autologous and fresh-frozen allogeneic block bone grafts for lateral ridge augmentation. Clinical oral implants research. 2014; 25(2):226-33.

28. Waasdorp J, Reynolds MA. Allogeneic bone onlay grafts for alveolar ridge augmentation: a systematic review. International Journal of Oral \& Maxillofacial Implants. 2010; 25(3).

29. Rose LF, Rosenberg E. Bone grafts and growth and differentiation factors for regenerative therapy: a review. Practical Procedures \& Aesthetic Dentistry. 2001; 13(9):725-34.

30. Canuto RA, Pol R, Martinasso G, Muzio G, Gallesio G, Mozzati M. Hydroxyapatite paste Ostim ${ }^{\circledR}$, without elevation of full-thickness flaps, improves alveolar healing stimulating BMP-and VEGF-mediated signal pathways: an experimental study in humans. Clinical oral implants research. 2013; 24(A100):42-8.

31. Blanco J, Mareque S, Linares A, Perez J, Munoz F, Ramos I. Impact of immediate loading on early bone healing at two-piece implants placed in fresh extraction sockets: an experimental study in the beagle dog. J Clin Periodontol 2013; 40: 421-9. 